\title{
Investigation of the mechanism of 1,2-migrations in methoxysiloxycarbene with the electron localization function
}

\author{
Paul G. Loncke, Timothy A. Gadosy, and Gilles H. Peslherbe* \\ Centre for Research in Molecular Modeling, and Department of Chemistry and Biochemistry, \\ Concordia University, Montréal, Québec, Canada. H3G 1 M8 \\ E-mail:ghp@alcor.concordia.ca
}

\section{Dedicated to Oswald S. Tee on the occasion of his $60^{\text {th }}$ birthday, and in recognition to his many contributions to chemistry in Canada \\ (received 03 Oct 01; accepted 04 Feb 02; published on the web 12 Feb 02)}

\begin{abstract}
A topological analysis of the gradient vector field of the electron localization function (ELF) has been used to investigate the mechanism of 1,2-silyl migration from oxygen to the carbene carbon in methoxysiloxycarbene. As well, the analogous 1,2-methyl migration was investigated for comparison. Plots of ELF isosurfaces and contour maps clearly reveal that the monosynaptic valence basin corresponding to the carbene lone pair becomes the disynaptic valence basin corresponding to the developing carbon-silicon bond in the transition state for 1,2-silyl migration, while it remains effectively unaltered in the transition state for 1,2-methyl migration. These results suggest that 1,2-silyl migration proceeds via nucleophilic attack by the carbene lone pair at silicon, whereas the energetically unfavorable 1,2-methyl migration appears to involve an anion-like shift from oxygen to the carbene center, in good agreement with previous findings.
\end{abstract}

Keywords: 1,2-Migrations, methoxysiloxycarbene, electron localization function (ELF)

\section{Introduction}

The most common intramolecular rearrangement reaction of singlet carbenes in solution is the 1,2-H shift. ${ }^{1-3}$ This rearrangement has been shown to involve a hydride-like shift from neighboring carbons to the vacant carbene p-orbital. ${ }^{4-7}$ Similarly, 1,2-migrations of other species such as alkyl, aryl, and halo groups, are believed to involve anion-like shifts from adjacent carbons to the vacant carbene p-orbital. ${ }^{1}$ In contrast, 1,2-migrations from neighboring oxygens to the carbene carbon are quite rare and mechanistically more complex. For instance, there is experimental and theoretical evidence indicating that 1,2-acyl migrations in 
phenyl(acyloxy)carbenes involve nucleophilic attack by the carbene lone pair at the acyl carbon. ${ }^{8}$ On the other hand, 1,2-allyl migrations in methoxy(allyloxy)carbenes have been shown to proceed via a fragmentation-recombination mechanism involving radicals, ${ }^{9}$ a mechanism that was further supported by $a b$ initio and density functional theory calculations. ${ }^{10}$ Similar findings have been reported recently for $p$-substituted benzyloxy(methoxy)carbenes ${ }^{11}$ and benzyloxy(benzyloxy)carbenes. ${ }^{12}$

Methoxytriphenylsiloxycarbene generated from an oxadiazoline precursor in benzene at $110{ }^{\circ} \mathrm{C}$ was recently reported to rearrange by 1,2-triphenylsilyl migration from oxygen to the carbene carbon, yielding methyl triphenylsilylformate. ${ }^{13}$ In contrast to the other dioxycarbene rearrangements $9,11,12$ mentioned earlier, radical trapping experiments indicate that these rearrangements do not involve radicals. Thus, the rearrangement mechanism could involve either an anion-like shift of the triphenylsilyl group from oxygen to the carbene $p$-orbital or nucleophilic attack by the carbene lone pair at the triphenylsilyl moiety. In an attempt to shed light onto the mechanism of this rearrangement, we studied 1,2-migrations in methoxysiloxycarbene as a model system, by means of $a b$ initio molecular orbital theory and hybrid density-functional theory calculations. ${ }^{14}$ As illustrated in Scheme 1, 1,2-silyl migration leads to formation of methyl silylformate, while 1,2-methyl migration affords silyl acetate. Detailed investigations based on frontier molecular orbital (FMO) theory, ${ }^{15}$ natural bond orbital (NBO) analysis, ${ }^{16}$ and the theory of atoms in molecules (AIM), ${ }^{17}$ were also carried out. All the evidence supports a mechanism involving nucleophilic attack by the carbene lone pair at silicon for 1,2-silyl migration, whereas 1,2-methyl migration seems to involve an anion-like shift of the methyl group from oxygen to the "vacant" carbene p-orbital. ${ }^{14}$ Since the latter mechanism involves the breaking of a bond with considerable double-bond character, it turns out to be energetically unfavorable. ${ }^{14}$ For instance, the relative Gibbs free energy barriers computed at the B3LYP/6-311+G(2d,p) level for 1,2-methyl migration are 45.3 and $46.0 \mathrm{kcal} / \mathrm{mol}$ compared to 9.6 and $10.8 \mathrm{kcal} / \mathrm{mol}$ for 1,2-silyl migration. Similar arguments would explain why product from 1,2-triphenylsilyl migration in methoxytriphenylsiloxycarbene are observed experimentally, but not from 1,2-methyl migration. ${ }^{13}$
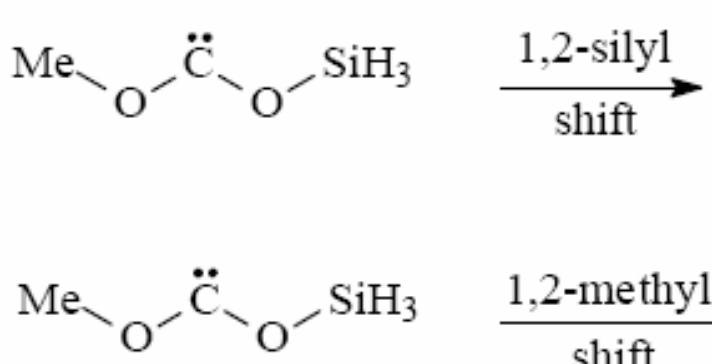

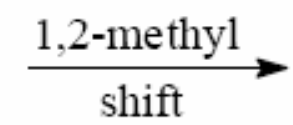

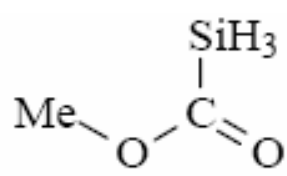

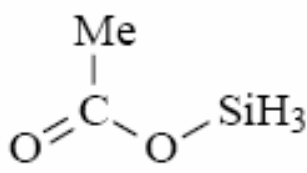

\section{Scheme 1}

In this article, we use yet another approach, the electron localization function (ELF) derived by Becke and Edgecombe, ${ }^{18}$ to elucidate the reaction mechanism for 1,2-migrations in 
methoxysiloxycarbene. The gradient vector field of ELF partitions the molecular space into regions or basins of localized electron pairs or attractors. ${ }^{19,20}$ There are basically two types of basins: core basins surrounding nuclei (with $\mathrm{Z}>2$ ) and valence basins in the remaining space. Each valence basin is characterized by its synaptic order, which is the number of core basins to which it is attached. Thus, a valence basin attached to one, two, or three core basins is described as monosynaptic, disynaptic, or trisynaptic, respectively. A disynaptic basin that contains a proton is referred to as a protonated valence basin. Core basins are denoted by $\mathrm{C}\left(\mathrm{X}_{\mathrm{i}}\right)$ and valence basins by $\mathrm{V}\left(\mathrm{X}_{\mathrm{i}}, \mathrm{X}_{\mathrm{j}}, \ldots\right)$, where $\mathrm{X}_{\mathrm{i}}$ is the atom label. Values of ELF, denoted by $\eta$, fall in the range $0 \leq \eta \leq 1$. An ELF value of 1.0 corresponds to perfect localization, while a value of 0.5 is equivalent to localization in a homogeneous electron gas (i.e. essentially delocalization).

Lewis-type and valence-shell electron-pair repulsion (VSEPR) representations of molecules can be inferred from the topology of ELF isosurfaces. The isosurfaces typically identify volumes within which Pauli repulsion is weak. The volumes, referred to as localization domains, are said to be irreducible if they contain only one attractor and reducible if they contain more than one attractor. At a low ELF isosurface value (e.g. $\eta=0$ ), a single reducible localization domain is obtained which encloses all attractors. As the value of ELF is increased, the single reducible localization domain is split into several domains with fewer attractors. In terms of Lewis and VSEPR models, monosynaptic valence basins correspond to lone pairs, disynaptic basins to twocenter bonds, trisynaptic to three-center bonds, and so on.

\section{Results and Discussion}

B3LYP/6-311+G(2d,p) calculations were carried out on the closed-shell singlet ( $\left.\mathrm{S}_{0}\right)$ state of methoxysiloxycarbene since oxycarbenes and dioxycarbenes are known to have large $\mathrm{S}_{0} \rightarrow \mathrm{T}_{1}$ gaps. ${ }^{14,21-23}$ Three ground-state conformers were identified for the carbene: a trans-trans conformer A, a cis-trans conformer $\mathbf{B}$ and a trans-cis conformer $\mathbf{C}$, which are shown in Figure 1. ${ }^{14}$ Atom labels are included in the figures for easy identification in the upcoming discussion. Based on the relative Gibbs free energies computed at the B3LYP/6-311+G(2d,p) level, A turns out to be more stable than both $\mathbf{B}$ and $\mathbf{C}$ by about $2.3 \mathrm{kcal} / \mathrm{mol}$. ConformerA undergoes both 1,2silyl and 1,2-methyl migrations, whereas conformers $\mathbf{B}$ and $\mathbf{C}$ only undergo 1,2-silyl and 1,2methyl migration respectively. ${ }^{14}$ Since the electronic structure of the carbene's reactive moieties are not significantly affected by conformational change, the rearrangement mechanisms of $\mathbf{B}$ and C are essentially the same as they are in A. Accordingly, we will only focus on the rearrangements in $\mathbf{A}$.

A plot of the ELF isosurface for A is displayed in Figure 2. There are five core basins (purple), four disynaptic valence basins (green), six protonated valence basins (blue) and three monosynaptic valence basins (orange). The five core basins, $\mathrm{C}(\mathrm{C} 1), \mathrm{C}(\mathrm{O} 2), \mathrm{C}(\mathrm{C} 6), \mathrm{C}(\mathrm{O} 7)$ and $\mathrm{C}(\mathrm{Si})$, have populations of $2.09,2.11,2.06,2.08$, and 10.06, respectively, which are essentially the number of electrons in the inner atomic shells. Note that the $\mathrm{C}(\mathrm{O} 2)$ and $\mathrm{C}(\mathrm{O} 7)$ basins can not 
be seen in the figure. The V(C6) monosynaptic valence basin corresponds to the carbene lone pair and has a population of 2.37 electrons. The $\mathrm{V}(\mathrm{O} 2)$ and $\mathrm{V}(\mathrm{O} 7)$ superbasins, with populations of 4.20 and 4.10 electrons, each represents the two lone pairs on the oxygens. The $\mathrm{V}(\mathrm{C} 1, \mathrm{O} 2)$, $\mathrm{V}(\mathrm{O} 2, \mathrm{C} 6), \mathrm{V}(\mathrm{C} 6, \mathrm{O} 7)$, and $\mathrm{V}(\mathrm{O} 7, \mathrm{Si})$ disynaptic valence basins have populations of $1.43,1.85$, 1.51, and 2.05 electrons. Hence, the picture that emerges from ELF analysis of $\mathbf{A}$ is in good agreement with Lewis and VSEPR representations of the carbene.

The barrier for methyl group rotation about the O2-C6 bond that leads from A to $\mathbf{B}$ was found to be considerably higher than that for silyl group rotation about the O7-C6 bond that leads from A to $\mathbf{C}$, suggesting that the $\mathrm{O} 2-\mathrm{C} 6$ bond is stronger than the $\mathrm{C} 6-\mathrm{O} 7$ bond. ${ }^{14}$ For instance, the B3LYP/6-311+G(2d,p) computed relative Gibbs free energy barrier is $17.9 \mathrm{kcal} / \mathrm{mol}$ for methyl group rotation versus $7.7 \mathrm{kcal} / \mathrm{mol}$ for silyl group rotation. This finding is supported by both the AIM analysis of the electron density at the bond critical points and NBO perturbationtheory energy analysis. ${ }^{14}$ As mentioned earlier, the populations of the $\mathrm{V}(\mathrm{O} 2, \mathrm{C} 6)$ and $\mathrm{V}(\mathrm{C} 6, \mathrm{O} 7)$ basins are 1.85 and 1.51 electrons respectively. If the basin populations for bonds between the same atoms are taken as a measure of the degree of electron pair localization and hence relative bond strengths, the present ELF analysis also means that the O2-C6 bond is stronger than the C6O7 bond.

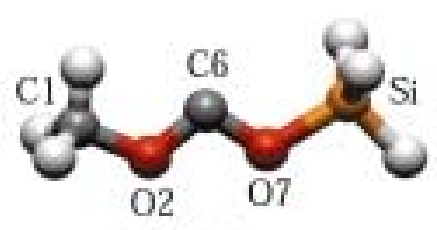

A

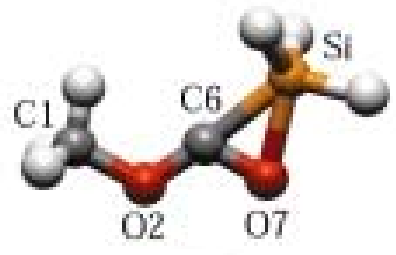

$\mathrm{TS}_{\mathrm{AD}}$

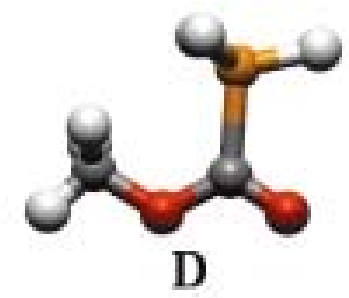

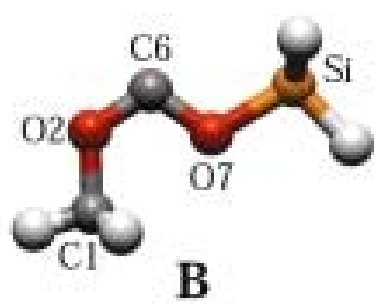


$\mathrm{TS}_{\mathrm{AF}}$

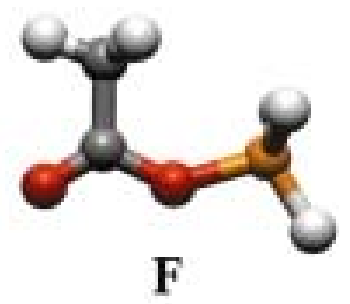

Figure 1. A, B, and C are the optimized geometric methoxysiloxycarbene conformers. TSAD and TSAF are transition-state geometries for 1,2-silyl and 1,2 methyl migrations that lead to $\mathbf{D}$ and $\mathbf{F}$. 
We now turn our attention to 1,2-silyl migration in methoxysiloxycarbene. The transition state for this rearrangement in $\mathbf{A}$ to give anti-methyl silylformate $\mathbf{D}$, hereafter referred to as TSAD, is shown in Fig. 1. A plot of the ELF isosurface for TSAD is shown in Fig. 2. The populations of the core basins in TSAD are 2.09, 2.08, 2.07, 2.12, and 10.06 electrons for $\mathrm{C}(\mathrm{C} 1)$, $\mathrm{C}(\mathrm{O} 2), \mathrm{C}(\mathrm{C} 6), \mathrm{C}(\mathrm{O} 7)$, and $\mathrm{C}(\mathrm{Si})$ respectively, essentially the same as those in $\mathrm{A}$. The $\mathrm{V}(\mathrm{C} 1, \mathrm{O} 2)$, $\mathrm{V}(\mathrm{O} 2, \mathrm{C} 6), \mathrm{V}(\mathrm{C} 6, \mathrm{O} 7)$ and $\mathrm{V}(\mathrm{O} 7, \mathrm{Si})$ disynaptic basins observed for $\mathbf{A}$ also appear in TSAD with populations of $1.51,1.75,1.76$, and 2.38 electrons, as well as the $\mathrm{V}(\mathrm{O} 2)$ and $\mathrm{V}(\mathrm{O} 7)$ superbasins with populations of 4.24 and 3.39 electrons. In contrast, the $\mathrm{V}(\mathrm{C} 6)$ monosynaptic basin corresponding to the carbene lone pair in A does not exists in TSAD. It is apparent from the ELF isosurfaces in Fig. 2 that the $\mathrm{V}(\mathrm{C} 6)$ monosynaptic basin in A becomes the V(C6,Si) disynaptic basin in TSAD with a population of 2.46 electrons. This finding, which is more apparent from a comparison of the ELF contours of A and TSAD in Fig. 2, is consistent with C6-Si bond formation via nucleophilic attack by the carbene lone pair at silicon.
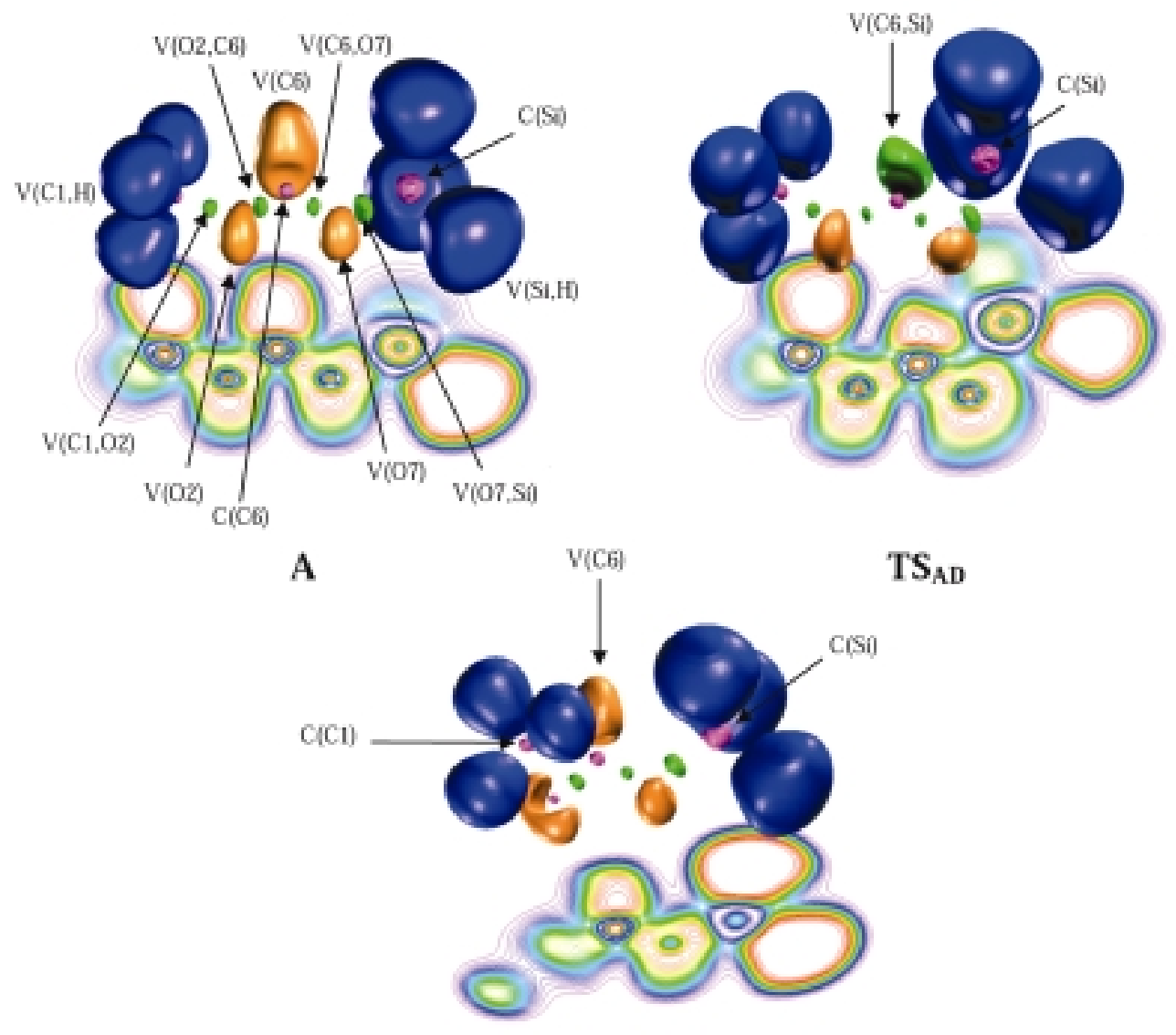

$\mathrm{TS}_{\mathrm{AF}}$

Figure 2. ELF isosurfaces and contour maps for A, TSAD, and TSAF. The values of $\eta$ for the isosurfaces are $0.850,0.860$, and 0.845 respectively. The color codes used for distinguishing the various basins are purple for core basins, orange for monosynaptic valence basins, green for disynaptic valence basins and blue for protonated valence basins. 
Now we turn our focus to 1,2-methyl migration in methoxysiloxycarbene for comparison and further mechanistic enlightenment. The transition-state for this rearrangement in $\mathbf{A}$ to afford antisilyl acetate $\mathbf{F}$, hereafter referred to as TSAF, is shown in Figure 1. An ELF isosurface plot for TSAF can be found in Figure 2. The $\mathrm{C}(\mathrm{C} 1), \mathrm{C}(\mathrm{O} 2), \mathrm{C}(\mathrm{C} 6), \mathrm{C}(\mathrm{O} 7)$, and $\mathrm{C}(\mathrm{Si})$ core basins have populations of $2.08,2.13,2.06,2.11$, and 10.06 electrons respectively, while the $\mathrm{V}(\mathrm{O} 2, \mathrm{C} 6)$, $\mathrm{V}(\mathrm{C} 6, \mathrm{O} 7)$ and $\mathrm{V}(\mathrm{O} 7, \mathrm{Si})$ valence basins have populations of $1.77,1.39$, and 2.14 electrons, about the same as those seen earlier for $\mathbf{A}$. The $\mathrm{V}(\mathrm{O} 2)$ superbasin observed in $\mathbf{A}$ splits into $\mathrm{V}_{1}\left(\mathrm{O}_{2}\right)$ and $\mathrm{V}_{2}(\mathrm{O} 2)$ monosynaptic basins in TSAF (not apparent in the figure), with populations of 2.67 and 2.69 electrons, which are akin to those of a carbonyl group, while the $\mathrm{V}(\mathrm{O} 7)$ superbasin is more or less the same with a slightly increased population of 4.11. Most significant, is the fact that the V(C6) monosynaptic basin corresponding to the carbene lone pair in A remains essentially unchanged in TSAF as can be seen in Fig. 2, and has a population of 2.24 electrons. This latter observation rules out the possibility of nucleophilic attack by the carbene lone pair at the methyl group. Also apparent in the figure is the fact that the $\mathrm{V}(\mathrm{C} 1, \mathrm{O} 2)$ basin in A disappears in TSAF, consistent with the breaking of the $\mathrm{C} 1-\mathrm{O} 2$ bond. Furthermore, there is a V(C1) monosynaptic basin that develops in TSAF with a population of 0.28 electrons, which unfortunately does not appear in Fig. 2 because of its low ELF value of 0.597. The appearance of this basin may be indicative of negative charge build-up at the methyl group, which would somewhat support a mechanism involving an anion-like shift of the methyl group.

Attempts to locate out-of-plane transition states for 1,2-silyl migration consistent with an anion-like shift of the silyl group from oxygen to the carbene carbon in $\mathbf{A}$ and $\mathbf{B}$ were unsuccessful. Similarly, efforts to locate in-plane transition states for 1,2-methyl migration indicative of nucleophilic attack by the carbene lone pair at methyl carbon in $\mathbf{A}$ and $\mathbf{C}$ proved futile. Apparently, the electropositive silicon being attached to highly electronegative oxygen is more electrophilic than even the carbene carbon. Consequently, 1,2-silyl migration preferentially involves nucleophilic attack by the carbene lone pair at silicon. On the other hand, the methyl carbon $\mathrm{C} 1$ bonded to $\mathrm{O} 2$ is less electrophilic than the carbene carbon and as a result, an anionlike shift of the methyl group from $\mathrm{O} 2$ to the "vacant" carbene p-orbital on C6 seems preferable.

In conclusion, it is apparent from the localization domains and contour maps of ELF that 1,2silyl migration involves nucleophilic attack by the carbene lone pair at silicon, whereas 1,2methyl migration occurs via an anion-like shift of the methyl group to the carbene carbon. The present ELF results are consistent with those of our previous analyses, which employed FMO theory, NBO and AIM. ${ }^{14}$

\section{Computational Methods}

Hybrid density-functional theory calculations at the Becke3 Lee-Yang-Parr (B3LYP) level ${ }^{24}$ with the $6-311+\mathrm{G}(2 \mathrm{~d}, \mathrm{p})$ basis set $^{25}$ were carried out with the Gaussian 98 suite of programs. ${ }^{26}$ Groundstate minimum energy geometries were optimized with the Berny algorithm ${ }^{27}$ while transition- 
state optimizations were performed using the eigenvector-following method. ${ }^{28-30}$ Topological analysis of the gradient vector field of the electron localization function (ELF) ${ }^{18}$ was carried out using the TopMod package of programs. ${ }^{31}$ Note that the ELF results presented here for B3LYP/6-311+G(2d,p) were not found to be very sensitive to the choice of model chemistry.

\section{Acknowledgements}

This work was funded by research grants from the Natural Science and Engineering Research Council (NSERC) of Canada, the Fonds pour la Formation des Chercheurs et l'Aide à la Recherche (FCAR, Québec) and the Faculty Research and Development Program (FRDP) of Concordia University. Calculations were performed at the Centre for Research in Molecular Modeling (CERMM), which was established with the financial support of the Concordia University Faculty of Arts \& Science, the Ministère de l'Éducation du Québec (MEQ) and the Canada Foundation for Innovation (CFI). The authors would like to thank Stéphane Noury and Heidi Muchall for helpful discussions regarding ELF.

\section{References and Notes}

1. Moss, R. A. In Advances in Carbene Chemistry; Brinker, U. H., Ed.; JAI Press Inc.: Greenwich, CT, 1994; Vol. 1; pp 59.

2. Liu, M. T. H. Acc. Chem. Res. 1994, 21, 287.

3. Schaefer, H. F. Acc. Chem. Res. 1979, 12, 288.

4. LaVilla, J. A.; Goodman, J. L. J. Am. Chem. Soc. 1989, 111, 6877.

5. Bonneau, R.; Liu, M. T. H.; Rayez, M. T. J. Am. Chem. Soc. 1989, 111, 5973.

6. Moss, R. A.; Ho, G.-J.; Liu, W. J. Am. Chem. Soc. 1992, 114, 959.

7. Liu, M. T. H.; Bonneau, R. J. Am. Chem. Soc. 1992, 114, 3604.

8. Moss, R. A.; Xue, S.; Liu, W.; Krogh-Jespersen, K. J. Am. Chem. Soc. 1996, 118, 12588.

9. Venneri, P. C.; Warkentin, J. J. Am. Chem. Soc. 1998, 120, 11182.

10. Reid, D. L.; Warkentin, J. J. Chem. Soc., Perkin Trans. 2 2000, 1980.

11. Merkley, N.; El-Saidi, M.; Warkentin, J. Can. J. Chem. 2000, 78, 356.

12. Merkley, N.; Warkentin, J. Can. J. Chem. 2000, 78, 942.

13. Pezacki, J. P.; Loncke, P. G.; Ross, J. P.; Warkentin, J.; Gadosy, T. A. Org. Lett. 2000, 2, 2733.

14. Loncke, P. G.; Gadosy, T. A.; Peslherbe, G. H. Can. J. Chem. in press, 2002.

15. Fleming, I. Frontier Orbitals and Organic Chemical Reactions; John Wiley \& Sons, Ltd.: Chichester, 1976.

16. Reed, A. E.; Curtiss, L. A.; Weinhold, F. Chem. Rev. 1988, 88, 899.

17. Bader, R. F. W. Atoms in Molecules. A Quantum Theory; Clarendon Press: Oxford, 1990. 
18. Becke, A. D.; Edgecombe, K. E. J. Chem. Phys. 1990, 92, 539.

19. Noury, S.; Colonna, F.; Savin, A.; Silvi, B. J. Mol. Struct. 1998, 450, 59.

20. Silvi, B.; Savin, A. Nature 1994, 371, 683.

21. Feller, D.; Borden, W. T.; Davidson, E. R. J. Chem. Phys. 1979, 71, 4987.

22. Sheridan, R. S.; Moss, R. A.; Wilk, B. K.; Shen, S.; Wlostowski, M.; Kesselmayer, M. A.; Subramanian, R.; Kmiecik-Lawrynowicz, G.; Krogh-Jespersen, K. J. Am. Chem. Soc. 1988, 110, 7563.

23. Moss, R. A.; Wlostowski, M.; Shen, S.; Krogh-Jespersen, K.; Matro, A. J. Am. Chem. Soc. 1988, 110, 4443.

24. (a) Becke, A. D. J. Chem. Phys. 1993, 98, 5648. (b) Lee, C.; Yang, W.; Parr, R. G. Phys. Rev. B 1988, 37, 785.

25. Hehre, W. J.; Radom, L.; Schleyer, P. v. R.; Pople, J. A. Ab Initio Molecular Orbital Theory; John Wiley \& Sons: New York, 1986.

26. Frisch, M. J.; Trucks, G. W.; Schlegel, H. B.; Scuseria, G. E.; Robb, M. A.; Cheeseman, J. R.; Zakrzewski, V. G.; J.A. Montgomery, J.; Stratmann, R. E.; Burant, J. C.; Dapprich, S.; Millam, J. M.; Daniels, A. D.; Kudin, K. N.; Strain, M. C.; Farkas, O.; Tomasi, J.; Barone, V.; Cossi, M.; Cammi, R.; Mennucci, B.; Pomelli, C.; Adamo, C.; Clifford, S.; Ochterski, J.; Petersson, G. A.; Ayala, P. Y.; Cui, Q.; Morokuma, K.; Malick, D. K.; Rabuck, A. D.; Raghavachari, K.; Foresman, J. B.; Cioslowski, J.; Ortiz, J. V.; Baboul, A. G.; Stefanov, B. B.; Liu, G.; Liashenko, A.; Piskorz, P.; Komaromi, I.; Gomperts, R.; Martin, R. L.; Fox, D. J.; Keith, T.; Al-Laham, M. A.; Peng, C. Y.; Nanayakkara, A.; Gonzalez, C.; M. Challacombe; Gill, P. M. W.; Johnson, B.; Chen, W.; Wong, M. W.; J. L. Andres; Gonzalez, C.; Head-Gordon, M.; Replogle, E. S.; Pople, J. A. Gaussian 98, Revision A.7, Gaussian, Inc.

27. Schlegel, H. B. J. Comp. Chem. 1982, 3, 214.

28. Bannerjee, A.; Adams, N.; Simons, J.; Shepard, R. J. Phys. Chem. 1985, 89, 52.

29. Simons, J.; Jorgensen, P.; Taylor, H.; Ozment, J. J. Phys. Chem. 1983, 87, 2745.

30. Cerjan, C. J.; Miller, W. H. J. Chem. Phys. 1981, 75, 2800.

31. Noury, S.; Krokidis, X.; Fuster, F.; Silvi, B. TopMod Manual. 